\title{
Does Tamsulosin use before Ureteroscopy Increase the Success of the Operation?
}

\author{
Murat Demir, Kasim Ertas, Rahmi Aslan, Recep Eryilmaz, Mehmet Sevim and Kerem Taken \\ Department of Urology, Faculty of Medicine, Van Yuzuncu Yil University, Van, Turkey
}

\begin{abstract}
:
Objective: To investigate the effect of preoperative tamsulosin use on the success and complications rates of ureteroscopy for ureteral stone removal.

Study Design: A randomised clinical trial.

Place and Duration of Study: Department of Urology, Dursun Odabas Medical Center, Van Yuzuncu Yil University, Turkey, from December 2020 to June 2021.

Methodology: Patients were scheduled for ureteroscopy due to ureteral stones, and were randomly divided into two groups; 67 patients preoperatively were given $0.4 \mathrm{mg}$ tamsulosin for 7 days and 70 patients were not given tamsulosin. Each patient's intraoperative surgical complications, preoperative and postoperative pain, postoperative fever, need for analgesia, stone-free rate, and double J ureteral stent (DJ) insertion rates were recorded and evaluated.

Results: A total of 137 patients, 103 (75.1\%) males, and 34 (24.8\%) females, were included. In 70 (51.1\%) of these patients, the stone was on the right side, while in $67(48.9 \%)$ the stone was on the left side. The stone was in the distal ureter in 47 (34.3\%) patients, in the middle in $38(27.7 \%)$ patients, and the proximal in $52(37.9 \%)$ patients. The patients who were given tamsulosin had lower preoperative visual analog scale $(p=0.02)$, operation time $(p=0.003)$, post-ureteroscopic lesion scale $(p=0.01)$, postoperative 24 th-hour visual analog scale $(p=0.03)$, fever $(p=0.02)$, and analgesic need $(p=0.04)$, while their rate of accessing the stone $(p=0.02)$; and their stone-free rates $(p=0.02)$ was higher.
\end{abstract}

Conclusion: Preoperative tamsulosin use increases the success of the operation and reduces complications.

Key Words: Tamsulosin, Ureteral calculi, Ureteroscopy.

How to cite this article: Demir M, Ertas K, Aslan R, Eryilmaz R, Sevim M, Taken K. Does Tamsulosin use before Ureteroscopy Increase the Success of the Operation?. J Coll Physicians Surg Pak 2022; 32(02):197-201.

\section{INTRODUCTION}

Ureteral stones are one of the most common diseases of urology. Twenty per cent of all stones in the urinary system are in the ureter, and these are mostly symptomatic. ${ }^{1}$ Ureteral stones can also cause deterioration in ipsilateral kidney function. Therefore, appropriate treatment should not be delayed in ureteral stones. ${ }^{2}$ Ureteral stone treatment consists of observation, medical expulsive therapy (MET), ureteroscopy (URS), and ureterolithotomy.,

Selective alpha-blockers are widely used in MET treatment. In many previously published meta-analyses, European Association of Urology and the American Association of Urology recommend this treatment, because it increases the rate of spontaneous stone passage of ureteral stones.

Correspondence to: Dr. Murat Demir, Department of Urology, Faculty of Medicine, Van Yuzuncu Yil University, Van, Turkey

E-mail: urologmurat72@gmail.com

Received: September 13, 2021; Revised: December 03, 2021; Accepted: December 22, 2021

DOI: https://doi.org/10.29271/jcpsp.2022.02.197
Alpha-blockers provide relaxation by blocking alpha receptors in ureteral smooth muscle. ${ }^{5,6}$ It also increases the rate of stone clearance after extra-corporeal shock wave therapy (ESWL). ${ }^{7}$ While these effects of alpha-blockers are well known, the effect of preoperative (pre-op) alpha-blocker use on URS success and complications in patients undergoing URS has not been adequately studied in the literature.

The aim of this study was to investigate the effect of tamsulosin use before URS on the success (defined as no residual stone larger than $3 \mathrm{~mm}$ ) of the operation, as well as both intraoperative (intra-op), and postoperative (post-op) complication rates.

\section{METHODOLOGY}

This prospective, randomised clinical trial was performed in the Department of Urology, Dursun Odabas Medical Center, Van Yuzuncu Yil University, Van, Turkey. The study was completed between December 2020 and June 2021 after receiving the approval of the local Ethics Committee (Decision No. 2020/09-18, date: 04.12.2020). Group 1 had 67 patients, who were given $0.4 \mathrm{mg}$ tamsulosin for 7 days preoperatively, and Group 2 had 70 patients, who were not given tamsulosin preoperatively. The patients were sequentially divided into groups on a 1:1 basis according to their order of admission. Patients older 
than 18 years of age, with a single stone larger than $7 \mathrm{~mm}$ and who agreed to participate were included in the study. This study excluded patients with stones smaller than $7 \mathrm{~mm}$, had an active infection or acute azotemia, a DJ stent or nephrostomy, a ureteral operation or known pathology, a solitary kidney, or were pregnant.

All patients were diagnosed with non-contrastcomputed tomography. Each patient's age and gender, as well as the stone's lateral location, localisation, and size, were recorded. Each patient's visual analog scale (VAS) score during the pre-op 7day period was recorded. The VAS is a scale that scores pain severity between 0 and 10 , in which 0 indicates no pain, and 10 indicates the most severe pain (Figure 1).

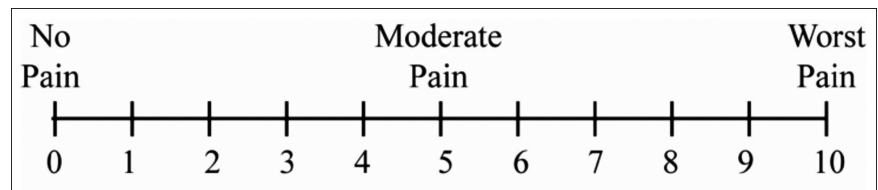

Figure 1: Visualanalogscale.

\begin{tabular}{|c|c|c|}
\hline \multicolumn{3}{|c|}{ Postureteroscopic Lesion Scale } \\
\hline Grade 0 & No lesion & Uncomplicated URS \\
\hline Grade 1 & $\begin{array}{l}\text { Superficial mucosal } \\
\text { lesion and/or } \\
\text { significant mucosal } \\
\text { edema/hematoma }\end{array}$ & $\begin{array}{l}\text { (no grading according } \\
\text { to the Dindo-modified } \\
\text { Clavien classification } \\
\text { of surgical }\end{array}$ \\
\hline Grade 2 & Submucosal lesion & complications) \\
\hline Grade 3 & $\begin{array}{l}\text { Perforation with } \\
\text { less than } 50 \% \\
\text { partial transsection }\end{array}$ & $\begin{array}{l}\text { Complicated URS } \\
\text { (Grade } 3 a \text { or } b \\
\text { according to the }\end{array}$ \\
\hline Grade 4 & $\begin{array}{l}\text { More than } 50 \% \\
\text { partial transsection }\end{array}$ & $\begin{array}{l}\text { Dindo-modified } \\
\text { Clavien classification }\end{array}$ \\
\hline Grade 5 & Complete transsection & $\begin{array}{l}\text { of surgical } \\
\text { complications) }\end{array}$ \\
\hline
\end{tabular}

URS $=$ ureterorenoscopy.

Figure 2: Postureteroscopic lesion scale.

After documenting negative urine cultures in all patients, pre-op single-dose intravenous $2 \mathrm{~g}$ ceftriaxone was given as prophylaxis. Then the patients were operated on with a ureterorenoscope (distal $8 \mathrm{fr}$ and proximal 9.8fr diameter). The cases, where the ureteral orifice could not be passed with the ureterorenoscope, were considered unsuccessful, and the operation was continued after the ureter was dilated with a balloon. Wolf laser device was used for lithotripsy at $1200 \mathrm{~mJ}$ and 2000 frequency. Intra-op complication rates wereevaluated with the post-ureteroscopic lesion scale (PULS, Figure 2). Intra-op stone access and DJ ureteral stent insertion data was recorded. Patients were given a post-op endoscopic examination, and kidney- ureter- bladder Xrays were taken, and patients with $\leq 3 \mathrm{~mm}$ residual stones were considered to be stone-free. Patients' temperatures were taken at a minimum of 4-hour intervals, and patients with a fever of $\geq$ $38^{\circ} \mathrm{C}$ in two measurements in the first 24 hours post-op were included in the febrile morbidity group. Patients were asked to fill in the VAS questionnaire at the post-op 24th hour. Alpha-blocker therapy was discontinued in all patients post-op. In addition, on the 21st post-op day, all patients' 21-day pain chart was evaluated with the VAS questionnaire. All this information was recorded by an observer, who did not know the patients that were given alpha-blockers. Nineteen patients with stones smaller than $7 \mathrm{~mm}$, and 10 patients with active infections or acute azotemia, patients with nephrostomy or DJ stents, ureteral pathology or history of operation, and solitary kidney, were excluded from the study because they could affect the success and complication rates of the surgery.

Descriptive statistics for continuous variables, while it is given as mean and standard deviation, it is given as numbers and percentages for categorical variables. Paired t-test was used for the comparison of post-op ( $24^{\text {th }}$-hour $\& 21^{\text {st }}$ day) and pre-op for VAS score. Studentt-test was used to compare groups in terms of continuous variables. The Chi-square test was used to determine the relationship between groups and categorical variables. The statistical significance level was taken as $5 \%$ in the calculations and the SPSS (version 21) statistical package programme was used for the calculations.

\section{RESULTS}

A total of 137 patients, 103 (75.1\%) males, and 34 (24.8\%) females, were included in this study. The mean age of those patients was $46.58 \pm 15.38(18-91)$ years. In 70 (51.1\%) of these patients, the stone was on the right side, while in $67(48.9 \%)$ patients, the stone was on the left side. The stone was in the distal ureter in 47 (34.3\%) patients, in the middle in $38(27.7 \%)$ patients, and the proximal in 52 (37.9\%) patients. The mean stone size was $11.45 \pm 4.65 \mathrm{~mm}$, and the mean operation time was $52.2 \pm 13.47$ minutes. Stone-free result was achieved in $110(80.2 \%)$ of these patients, while residual stones were seen in $27(19.7 \%)$ patients. DJ stent was placed in $113(82.4 \%)$ patients.

Table l: Comparison between groups.

\begin{tabular}{|c|c|c|c|c|}
\hline & Group 1 (n:67) & Group 2 (n:70) & p-value \\
\hline \multicolumn{2}{|l|}{ Age } & $47.44 \pm 16,79$ & $45.75 \pm 13,96$ & 0.522 \\
\hline \multicolumn{2}{|c|}{ Stone size } & $10.94 \pm 4,53$ & $11.95 \pm 4,74$ & 0.202 \\
\hline \multicolumn{2}{|c|}{ Reaching the stone } & $63(94 \%)$ & $57(81 \%)$ & $0.02 *$ \\
\hline \multicolumn{2}{|c|}{$\begin{array}{l}\text { Operation duration } \\
\text { (minutes) }\end{array}$} & $48.80 \pm 14,19$ & $55.50 \pm 11.95$ & $0.003^{*}$ \\
\hline \multicolumn{2}{|c|}{ Stone free } & $59(88 \%)$ & $51(72.85 \%)$ & $0.02 *$ \\
\hline \multicolumn{2}{|l|}{ DJ } & $51(76.11 \%)$ & $62(88.57 \%)$ & 0.055 \\
\hline \multicolumn{2}{|l|}{ Fever } & $6(8.95 \%)$ & $16(22.85 \%)$ & $0.02 *$ \\
\hline \multicolumn{2}{|c|}{ Analgesia } & $15(22.38 \%)$ & $52(74.28 \%)$ & $0.04 *$ \\
\hline \multirow{3}{*}{ VAS } & Pre-op & $4.52 \pm 0.65$ & $4.82 \pm 0.90$ & $0.02 *$ \\
\hline & $\begin{array}{l}\text { Post-op } \\
24^{\text {th }} \text { hour }\end{array}$ & $2.22 \pm 0.64$ & $2.44 \pm 0.58$ & $0.03 *$ \\
\hline & $\begin{array}{l}\text { Post-op } \\
21^{\text {st }} \text { day }\end{array}$ & $1.52 \pm 0.56$ & $1.57 \pm 0.55$ & 0.6 \\
\hline PULS & $\begin{array}{l}\text { Grade } 1 \\
\text { Grade } 2 \\
\text { Grade } 3\end{array}$ & $\begin{array}{c}51(76.11 \%) \\
13(19.4 \%) \\
3(4.47 \%)\end{array}$ & $\begin{array}{c}38(54.28 \%) \\
28(4 \%) \\
3(4.28 \%)\end{array}$ & $0.019 *$ \\
\hline \multicolumn{5}{|c|}{$\begin{array}{l}\text { *In Group 1, the rate of reaching the stone and the stone-free rate was } \\
\text { significantly higher, while the operation time, preoperative and post- } \\
\text { operative 24th hour VAS were significantly lower (Paired t-test). *Fever, } \\
\text { analgesic requirement and PULS values were significantly lower in Group } 1 \\
\text { (Chi-square test). *DJ: Double J, *VAS: Visual Analog Scale, *PULS: Post } \\
\text { ureteroscopic lesion scale. }\end{array}$} \\
\hline
\end{tabular}


Forty-two patients (30.6\%) needed post-op analgesia. Fever developed in 22 (16\%) patients. The operation time of the patients with a fever was $63.18 \pm 10.63$ minutes, while the duration of the operation for patients without fever was $50.13 \pm$ 12.96 minutes $(p=0.001)$. No significant difference was observed between the groups in terms of age and stone size. A statistically significant difference was observed in the alphablocker group compared to the non-user group in terms of reaching the stone, pre-op VAS, post-op 24th-hour VAS, operation time, stone-free rate, PULS, post-op fever, and need for analgesia (Tablel).

\section{DISCUSSION}

Appropriate treatment selection is important after the diagnosis of ureteral stones. Stone size is one of the most important factors in choosing a treatment. While stones smaller than $3 \mathrm{~mm}$ are clinically insignificant, stones larger than 7-10 mm are not expected to spontaneously pass. For stones between 3-10 mm, alpha-blockers are given to provide spontaneous stone passage. Alpha-blockers provide relaxation of the ureter by blocking alpha receptors in the ureteral smooth muscles. This treatment is called MET; and with this treatment, $65 \%$ of stones are able to pass spontaneously. Studies suggest using URS for stones larger than $10 \mathrm{~mm}$ or for stones that do not spontaneously pass with the MET treatment..$^{8-11}$

Since URS is a minimally invasive method, recently it has become the primary treatment for ureteral stones. However, URS has complications such as hematuria, ureteral avulsion, fever, sepsis, and pain that may develop. ${ }^{12}$ In some studies, it has been reported that pre-op alpha-blocker treatment facilitates URS and shortens the operation time. ${ }^{13,14}$ In this study, it was shown that alpha-blocker treatment shortened the operation time, increased the success rate, decreased intra-op and post-op complications, as well as pre-op and post-op pain.

One of the most important problems in the application of the URS treatment is the difficulty in inserting the URS into the ureteral orifice. Due to the narrow diameter of the orifice, entry into the ureter may be unsuccessful. One of the reasons for this is that alpha-receptors, which are densely located in the distal ureteral smooth muscles, provide smooth muscle contraction. With the effect of alpha-blockers, this contraction is prevented and passive dilatation is provided. Studies have reported that the ureteral orifice of patients using alpha-blockers before ureteroscopy is more open, more visible, and easier to pass. This means less time is needed to pass the orifice, less mucosal damage, and a lower complication rate. ${ }^{14-16}$ In this study, ureteral access was easier in the group using alpha-blockers, and the results were in accordance with the literature.

One of the most important factors in the treatment of ureteral stones is pain management, as ureteral stones cause severe colic pain. Many treatment methods and analgesia types have been investigated to prevent renal colic. For this reason, non-steroidal anti-inflammatory agents, like ketorolac and other narcotics have been used, but none of these drugs are without side effects. Therefore, it is important to reduce the severity of renal colic. ${ }^{8,17}$ In this study, the pre-op pain score of the alphablocker group was lower than in Group 2. Pain management in post-op patients is also important. Even though post-op pain is considered to be a minor complication, many patients suffer from pain after surgery. In a study, it was observed that in $57 \%$ of patients, the pain developed after URS. ${ }^{18}$ The causes of early post-op pain are not clear. While one of the factors associated with post-op pain is prolonged operation time, the most common factors that are associated with post-op pain are stretching of the renal capsule, extravasation of irrigation fluid, and ureteral obstruction by stone particles and blood clots due to edema in the ureter. ${ }^{19}$ In a study by Tanriverdi et al., $8.3 \%$ of patients who did not have a DJ stent placed during URS operation, needed stent placement in the post-op period and reported that almost all of the pain in the re-performed URS was caused by diffuse edema in the ureter. ${ }^{18}$

Pain due to ureteral edema occurs in the first 24 hours postoperatively. ${ }^{19}$ However, contrary to this study, there is a study stating that patients with stents suffer from more pain than patients without stents. ${ }^{20}$ This is due to DJ stent-induced trigone of bladder irritation. In addition, it has been reported that DJ stents can also cause hematuria, sexual dysfunction, suprapubic, and flank pain other than irritative bladder symptoms. ${ }^{18,20}$

Studies have reported that alpha-blockers relieve irritative bladder symptoms and suprapubic pain, and improve sexual symptoms. In addition, it has also been reported that abnormal contractions develop in the ureter after URS and that the resulting reflux causes colic pain. Alpha-blockers have been shown to reduce pain by blocking alpha receptors in the ureter. ${ }^{20}$ The most effective analgesics after URS are NSAIDs and narcotics. However, in addition to NSAll-induced nephrotoxicity and liver failure, there is a risk of anaphylaxis with some NSAIDs. ${ }^{21,22}$ In narcotic analgesics, there are risks of addiction and death due to overdose, as well as liver and kidney failure. ${ }^{23,24}$ Therefore, it is important to reduce the need for analgesics afterURS.

This study showed that alpha-blockers reduce both pre-op and post-op pain. In addition, the level of post-op analgesic use was also lower. The reason for this was thought to be the shortened operation time due to the dilated ureter, enabling us to reach the stone in a shorter time, the lower rate of obstruction by blood clots and stone particles, and less irritation of the wall of the ureter by the $D$ J stent.

Fever develops in 2-15\% of patients after a URS operation. Studies have shown that a positive urine culture is the most common cause of fever after ureteroscopy; but when a negative urine culture is documented, the most common cause of fever is the operation time, which is determined by the complexity of the operation. In addition, despite a negative urine culture, postoperative fever and even sepsis can be seen, as urine that cannot drain due to impacted ureteral stones becomes infected. Bacteria in the urine enter the systemic circulation due 
to intraoperative mucosal laceration and increased hydrostatic pressure. Therefore, pre-op antibiotic prophylaxis and post-op fever follow-up are recommended even if the urine culture is negative. ${ }^{16,18,25}$ In this study, a significantly lower rate of post-op fever was observed in the group using alpha-blockers. It was thought that the rate of post-op fever in patients decreased because alpha-blockers shortened the operation time. In addition, the authors estimate that facilitating urinary drainage due to the relaxation of the ureter by the alpha-blocker may also have contributed to the lower post-op fever rate.

One of the limitations of this study was that there was no preoperative assessment of the ureteral orifice.

\section{CONCLUSION}

Preoperative use of alpha-blockers reduces intra-op and postop complications and increases patient comfort. Therefore, a pre-op alpha-blocker may be beneficial not only for MET but also for all patients scheduled for URS due to ureteral stones.

\section{ETHICALAPPROVAL:}

The approval of the local Ethics Committee was received (Decision No. 2020/09-18, date: 04.12.2020).

\section{PATIENTS' CONSENT:}

All patients were included in the study after obtaining a written consentform.

\section{CONFLICT OF INTEREST:}

The authors declared no conflict of interest.

\section{AUTHORS' CONTRIBUTION:}

$M D, K E, R A, R E, M S, K T$ : Collected and analysed data, wrote manuscript, searched literature, and designed study.

\section{REFERENCES}

1. Bangash M, Nazim SM, Jamil S, Ghani MOA, Naeem S. Efficacy and safety of semi-rigid ureteroscopic lithotripsy (URS) for proximal ureteral stone $\geq 10 \mathrm{~mm}$. J Coll Physicians Surg Pak 2020; 30(10):1058-62. doi: 10.29271/jcpsp. 2020.10.1058.

2. Wang SJ, Mu XN, Zhang LY, Liu QY, Jin XB. The incidence and clinical features of acute kidney injury secondary to ureteral calculi. Urol Res 2012; 40(4):345-8. doi: 10. 1007/s00240-011-0414-6.

3. Radfar MH, Valipour R, Narouie B, Sotoudeh M, Pakmanesh $\mathrm{H}$. Role of the gonadal vessels on the stone lodgment in the proximal ureter: Direct observation during laparoscopic ureterolithotomy. Arch Italiano di Urologia e Androl 2018; 90(3):163-5. doi: 10.4081/aiua.2018.3.163.

4. Yuceturk CN, Dadali M, Bagbanci MS, Ozgur BC, Aydogmus $Y$, Yildiz $Y$, et al. Efficacy of silodosin dose in medical expulsive therapy for distal ureteral stones: A Retrospective Study. Urol J 2017; 14(1):2944-8.

5. Turk C, Knoll T, Seitz C, Skolarikos A, Chapple C, McClinton S. European association of urology. Medical expulsive therapy for ureterolithiasis: The EAU recommendations in 2016. Eur Urol 2017; 71(4):504-7. doi: 10.1016/j.eururo. 2016.07.024.
6. Conway JC, Friedman, BW. Medical expulsive therapy (alpha blockers) for urologic stone disease. Acad Emerg Med 2020; 27(9):923-4. doi: 10.1111/acem.13935.

7. Oestreich MC, Vernooij RW, Sathianathen NJ, Hwang EC, Kuntz GM, Koziarz A, et al. Alpha-blockers after shock wave lithotripsy for renal or ureteral stones in adults. Cochrane Database Syst Rev 2020; 11(11):1-3.doi: 10.1002/ 14651858.CD013 393.pub2.

8. Pickard R, Starr K, MacLennan G, Lam T, Thomas R, Burr J, et al. Medical expulsive therapy in adults with ureteric colic: $A$ multicentre, randomised, placebo-controlled trial. Lancet 2015; 386 (9991): 341-9. doi: 10.1016/S0140-6736 (15)60933-3.

9. Kukreja Rajesh A. "Should mini percutaneous nephrolithotomy (MiniPNL/Miniperc) be the ideal track for mediumsized renal calculi (15-30 mm)?." World J Urol 2018; 36(2): 285-91. doi: 10.1007/s00345-017-2128-z.

10. Li X, Zhu W, Lam W, Yue Y, Duan H, Zeng G. Outcomes of long-term follow-up of asymptomatic renal stones and prediction of stone-related events. BJU Int 2019; 123(3): 485-92. doi: 10.1111/bju.14565.

11. De Coninck V, Antonelli J, Chew B, Patterson JM, Skolarikos A, Bultitude M. Medical expulsive therapy for urinary stones: Future trends and knowledge gaps. Eur Urol 2019; 76(5): 658-66. doi: 10.1016/j.eururo.2019.07.053.

12. De Coninck V, Keller EX, Somani B, Giusti G, Proietti S, Rodriguez-Socarras $M$, et al. Complications of ureteroscopy: A complete overview. World J Urol 2020; 38(9):2147-66. doi: 10.1007/s00345-019-03012-1.

13. Alsaikhan B, Koziarz A, Lee JY, Pace KT. Preoperative alphablockers for ureteroscopy for ureteral stones: A systematic review and meta-analysis of randomised controlled trials. J Endourol 2020; 34(1):33-41. doi: 10.1089/end.2019.0520.

14. Tan H, Li Y, Zhang X, Mao X. Pooled analysis of the efficacy and safety of adjunctive alpha-blocker therapy before ureteroscopy in the management of ureteral stones. J Int Med Res 2020; 48(6): 1-10. doi: 10.1177/0300060 520923878.

15. Mohey A, Gharib TM, Alazaby H, Khalil M, Abou-Taleb A, Noureldin YA. Efficacy of silodosin on the outcome of semirigid ureteroscopy for the management of large distal ureteric stones: blinded randomized trial. Arab J Urol 2018; 16(4):422-8. doi: 10.1016/j.aju.2018.07.002.

16. Abdelaziz AS, Kidder AM. Tamsulosin therapy improved the outcome of ureterorenoscopy for lower ureteral stones: A prospective, randomised, controlled, clinical trial. Afr J Urol 2017; 23(2):148-53.

17. Davenport K, Waine E. The role of non-steroidal antiinflammatory drugs in renal colic. Pharmaceuticals (Basel) 2010; 3(5):1304-10. doi: 10.3390/ph3051304.

18. Hamidi N, Ozturk E, Yikilmaz TN., Atmaca AF, Basar H. The effect of corticosteroid on postoperative early pain, renal colic, and total analgesic consumption after uncomplicated and unstented ureteroscopy: A matched-pair analysis. World J Urol 2018; 36(6):979-84. doi: 10.1007/ s00345-018-2210-1.

19. Tanriverdi O, Yencilek F, Koyuncu H, Yencilek E, Sarica K. 
Emergent stenting after uncomplicated ureteroscopy: Evaluation of 23 patients. Urology 2011; 77(2):305-8. doi: 10.1016/j.urology.2010.07.472.

20. Lee C, Kuskowski M, Premoli J, Skemp N, Monga M. Randomised evaluation of ureteral stents using validated symptom questionnaire. J Endourol 2005; 19(8):990-3. doi: 10.1089/end.2005.19.990.

21. Yousefi H, Sahebi A, Farahani M, Golitaleb M. Anaphylaxis is a rare side effect of ketorolac: A case report. Arch Emerg Med 2020; 8(1):1-3.

22. Jalili M, Shirani F, Entezari P, Hedayatshodeh M, Baigi V, Mirfazaelian H. Desmopressin/indomethacin combination efficacy and safety in renal colic pain management: a randomised placebo controlled trial. Am J Emerg Med
2019; 37(6):1009-2. doi: 10.1016/j.ajem.2018.08.033.

23. Talwar R, Dobbs RW, Stambakio H, Lin G, Tasian GE, Ziemba JB. A longitudinal cohort study of pain intensity and interference after ureteroscopy for nephrolithiasis without postoperative opioids. Urololgy 2021; 147:81-6. doi: 10.1016/j.urology.2020.09.042.

24. Fedrigon D, Faris A, Kachroo N, Jain R, Elia M, Wilkins L, et al. SKOPE - study of ketorolac vs. opioid for pain after endoscopy: A double-blinded randomized control trial in patients undergoing ureteroscopy. J Urol 2021; 206(2): 10-97. doi: 10.1097/JU.0000000000001772.

25. Okcelik S, Kurul NO, Kiziloz H, Temel MC, Yesildal C. Factors affecting success of semi-rigid ureterorenoscopy in proximal ureter stone treatment. J Coll Physicians Surg Pak 2021; 31(1):65-9. doi: 10.29271/jcpsp.2021.01.65. 